\title{
Influência do parasitismo pelo nematoide de galhas nos níveis de nutrientes em folhas e na fenologia de goiabeira 'Paluma'
}

\author{
Eduardo José de Almeida $\left({ }^{*}\right)$; Jaime Maia dos Santos ( $\left.{ }^{1}\right)$; Antonio Baldo Geraldo Martins $\left({ }^{2}\right)$ \\ (') Universidade Estadual Paulista (UNESP/FCAV), Departamento de Fitossanidade, Via de acesso Prof. Paulo Donato Castellane, s/n, \\ 14884-900 Jaboticabal (SP), Brasil. \\ (2) UNESP/FCAV, Departamento de Produção Vegetal, 14884-900 Jaboticabal (SP), Brasil. \\ (*) Autor correspondente: E-mail: eduardo.almeida@fcav.unesp.br
}

Recebido: 5/jan./2011; Aceito: 19/ago./2011

\section{Resumo}

A redução no vigor de goiabeiras parasitadas por Meloidogyne enterolobii é consequência das alterações ocorridas no sistema radicular que desencadeia uma síndrome caracterizada por desequilíbrio nutricional. Para caracterizar esse desequilíbrio, foram efetuadas análises químicas de folhas com três tipos de sintomas visuais (folhas sem sintoma, com sintoma leve e sintoma severo) de goiabeiras 'Paluma', em duas épocas: fevereiro e agosto. As plantas foram cultivadas com e sem inoculação de Meloidogyne enterolobii por dois anos em microparcelas. Os teores de N, P e K decresceram em folhas sem sintomas para folhas com sintoma leve e severo nas análises realizadas nas duas épocas. O Ca teve sua concentração aumentada com o agravamento dos sintomas, em ambas as épocas. Em fevereiro, não houve alteração em Mg, mas em agosto sua concentração foi maior em folhas com sintoma severo do que em folhas com sintoma leve ou sem sintoma. O S teve uma concentração maior em folhas sem sintoma, em fevereiro, e em agosto as folhas com sintoma severo tiveram as maiores concentrações desse nutriente. O teor de B não diferiu quanto à presença ou ausência de sintomas e a épocas de análise. 0 Cu e o Fe tiveram aumento de concentração em fevereiro em folhas com ausência de sintoma para as folhas com sintoma severo. O teor de $\mathrm{Zn}$ reduziu com o aumento dos sintomas visuais nas folhas nas duas épocas de avaliação. A fenologia da goiabeira 'Paluma' não foi influenciada pelo parasitismo de M. enterolobii na primeira florada.

Palavras-chave: deficiência nutricional, nutrição mineral, nematoide das galhas, fruticultura.

\section{Influence of Meloidogyne enterolobii parasitism on leaf nutritional status and phenology of 'Paluma' guava plants}

\section{Abstract}

The reduction in vigor of guava infected by Meloidogyne enterolobii is a consequence of changes in root system, with this infection triggering a syndrome characterized by symptoms related to nutritional imbalance. To characterize it, chemical analyses were performed in three types of leaves (leaves without symptoms, with symptoms considered mild and severe) and also in soil in two periods: February and August. The plants were grown for two years with and without inoculation of the guava nematode. The concentrations of N, P and K decreased in leaves without symptoms compared with leaves with mild and severe symptom in the analysis carried out in both seasons. Ca concentration was increased with the worsening of symptoms in both seasons. Mg concentration did not change in February, but in August it also had its highest concentration in leaves with severe symptoms different from the leaves with mild or without symptoms. Leaf S concentration was higher in leaves without symptoms in the analysis conducted in February, whereas in August, the leaves with severe symptoms had higher $\mathrm{S}$ concentrations. The concentration of B did not differ regarding the presence or absence of symptoms and time of analysis. In February, Cu and Fe concentrations were increased in leaves with severe symptoms. The concentration of Zn decreased with increasing the severity of leaf visual symptoms in both times of assessment. The phenology of guava cultivar Paluma was not affected by infection of $M$. enterolobii at the first flowering.

Key words: nutritional imbalance, mineral composition of plants, rootknot nematodes. 


\section{INTRODUÇÃO}

A infecção de goiabeiras por Meloidogyne enterolobii Yang \& Eisenback (sinonímia Meloidogyne mayaguensis Ramah \& Hirschmann) desencadeia uma síndrome caracterizada por declínio da planta, sintomas foliares de amarelecimento, manchas avermelhadas, necrose, murcha e abscisão prematura, os troncos perdem a escamação característica da família Myrtaceae e tornam-se acinzentados, diante de maior exposição ao sol e, posteriormente, ocorre morte precoce da planta (CARNeiro et al., 2001).

A redução no vigor das goiabeiras parasitadas pelo nematoide é consequência das alteraçốes ocorridas no sistema radicular, ocasionando distúrbios nos mecanismos de absorção e transporte de água e nutrientes (BARKER et al., 1998).

Segundo Gomes et al. (2008), até o momento, o declínio causado pelo $M$. enterolobii em goiabeiras não foi caracterizado, pois não são conhecidos os fatores que contribuem para a morte das plantas. Nesse contexto, Perri e Moens (2005) afirmaram que os sintomas decorrentes de patossistemas envolvendo espécies de Meloidogyne são devidos a processos tais como a obstrução dos vasos condutores, alteração no padrão de absorção e ou translocaçâo de água e de nutrientes e alteraçóes fisiológicas.

Sintomas de deficiência nutricional em plantas é a expressão de distúrbios metabólicos resultantes do suprimento insuficiente de um ou mais elementos essenciais. Tais problemas estáo relacionados às funçóes desempenhadas pelos nutrientes no metabolismo e no funcionamento normal da planta (Taiz e Zeiger, 2004). Esse suprimento insuficiente de nutrientes às plantas pode ser acarretado pelos danos causados por nematoides nas raízes das plantas. Dessa forma, a composição mineral das plantas parasitadas por nematoides, usualmente, difere da composição de plantas sadias. Essas alterações na composição mineral não seguem um padrão rígido, podendo ocorrer, em alguns casos, diminuição ou acúmulo ou, ain$\mathrm{da}$, permanecerem inalterados os teores de determinados nutrientes (Hussey, 1985).

Outra influência da infecção de nematoides é quanto à fenologia da planta. O comportamento das plantas quanto ao florescimento e à frutificação pode variar em razão de uma série de fatores (genéticos, ambientais e de manejo dos pomares) tais como tipo e posiçấo das flores nos ramos, deiscência da antera, clima, solo, espaçamento entre plantas, estado nutricional e poda (CORRÊA et al., 2002).

O presente trabalho teve como objetivo avaliar o efeito da infecçấo por M. enterolobii na concentraçáo de nutrientes nas folhas e na fenologia de goiabeiras da cultivar Paluma.

\section{MATERIAL E MÉTODOS}

O experimento foi desenvolvido em microparcelas construídas com manilhas de cimento de $1 \mathrm{~m}$ de altura por
$0,80 \mathrm{~m}$ de diâmetro, introduzidas verticalmente no solo até $0,90 \mathrm{~m}$, com $0,10 \mathrm{~m}$ acima do nível do solo, a céu aberto. O local do experimento tem como coordenadas $21^{\circ} 15^{\prime} \mathrm{S}$ de latitude, $48^{\circ} 18^{\prime} \mathrm{W}$ de longitude e 590 $\mathrm{m}$ de altitude. $\mathrm{O}$ clima da regiấo é do tipo Cwa (clima temperado úmido com inverno seco e verão quente), de acordo com a classificação de Köeppen, com precipitaçâo pluvial em torno de $1.350 \mathrm{~mm}$ por ano. O espaçamento entre as plantas foi $2,10 \times 2,10$ nas microparcelas, as quais foram irrigadas com 12 a 15 litros de água, três vezes por semana de abril a setembro (em época seca). As manilhas foram preenchidas com material de solo da classe Argissolo Vermelho Distrófico, previamente autoclavado a $120^{\circ} \mathrm{C}$ por 1 hora.

Mudas de goiabeira 'Paluma', produzidas em substrato orgânico constituído por casca de pinus carbonizada e isento de nematoides, foram transplantadas para as microparcelas e, nesse momento, submetidas à inoculaçáo com os níveis de inóculo contendo 0 (testemunha), 10 e 100 ovos + juvenis de segundo estádio (J2) por planta de M. enterolobii em $10 \mathrm{~mL}$ de suspensão aquosa, conforme método de Hussey e Barker (1973). A cada período alternado de 30 dias, no período chuvoso, as plantas foram adubadas com $60 \mathrm{~g}$ da formulação 20-00-20 de NPK ou $40 \mathrm{~g}$ de termofosfato magnesiano Yoorin (18\% de P e 7\% de $\mathrm{Mg}$ ). Nos períodos de maior déficit hídrico (abril a setembro), a cada 60 dias, as plantas receberam a mesma dose dos referidos adubos.

No segundo ano após a inoculação do nematoide nas raízes das goiabeiras, foram realizadas amostragens de solo e de folhas dessas plantas com e sem sintomas foliares decorrentes da infecçáo pelo nematoide para a determinação das concentraçóes de macro e micronutrientes. As coletas foram efetuadas em agosto (inverno) e fevereiro (verão). As amostras de material da parte aérea foram constituídas pelo terceiro ou quarto par de folhas, abaixo da extremidade dos ramos, conforme recomendado por Natale et al. (1996). Nessa época, foi realizada amostragem das raízes das plantas para análise nematológica a qual indicou que, nas parcelas que não receberam o nematoide, não houve presença de $M$. enterolobii e nas plantas submetidas à inoculação com 100 ovos + J2 ocorreu, em média, 12.800 nematoides $/ 10 \mathrm{~g}$ de raízes.

$\mathrm{O}$ experimento foi desenvolvido em delineamento inteiramente casualizado com 10 microparcelas contendo uma goiabeira em cada uma delas, totalizando 10 plantas por tratamento.

Cada análise foi feita retirando-se três pares de folhas de cada uma das 10 plantas, somando cerca de 60 folhas. Posteriormente, divididas aleatoriamente em três repetiçóes para as análises químicas, separando-as em três estágios de sintomas: folhas sem sintomas visuais de deficiência nutricional ou ataque de pragas, com tamanho considerado normal e coletadas em plantas não- 
inoculadas; folhas com sintomas leves, ou seja, início de "arroxeamento" nos bordos, com tamanho normal ou menor; e folhas com sintomas severos, com a maior parte da sua área arroxeada tamanho significativamente menor que uma folha normal.

As análises das concentraçôes de nutrientes nas folhas e no solo foram efetuadas segundo Tedesco et al. (1995), sendo os dados submetidos à análise de variância e as médias comparadas pelo teste de Tukey a $5 \%$ de probabilidade.

$\mathrm{Na}$ avaliação da fenologia das plantas, aos 22 meses do plantio, os botóes emitidos nos ramos produtivos das goiabeiras inoculadas e das não-inoculadas com $M$. enterolobii, foram marcados com etiqueta confeccionada em folha de papel vegetal de cerca de $4 \times 4 \mathrm{~cm}$. Essas etiquetas continham anotaçôes a lápis das datas dos eventos fenológicos (emissão do botão floral, antese e estádio de maturação dos frutos) e o número do botáo floral, fixadas ao pedúnculo de cada botão floral, com auxílio de um barbante de cerca de $20 \mathrm{~cm}$ de comprimento. As avaliaçóes foram feitas a cada dois dias. A variância dos dados relativos às eventualidades foi avaliada pelo teste $\mathrm{F}$ e as médias comparadas pelo teste de Tukey a $5 \%$ de probabilidade com números diferentes de repetiçóes.

Tabela 1. Análise química do solo das microparcelas coletado em agosto e fevereiro

\begin{tabular}{lcc} 
Características químicas & Agosto & Fevereiro \\
$\mathrm{pH} \mathrm{CaCl}$ & 4,8 & 4,6 \\
$\mathrm{Ca}^{2+}\left(\mathrm{mmolc} \mathrm{dm}^{-3}\right)$ & 18 & 22 \\
$\mathrm{Mg}^{2+}\left(\mathrm{mmolc} \mathrm{dm}^{-3}\right)$ & 15 & 18 \\
$\mathrm{~T}\left(\mathrm{mmolc} \mathrm{dm}^{-3}\right)$ & 66,8 & 90,4 \\
$\mathrm{H}+\mathrm{Al}\left(\mathrm{cmol}_{c} \mathrm{dm}^{-3}\right)$ & 47 & 47 \\
$\mathrm{~V}(\%)$ & 59 & 48 \\
Matéria Orgânica $\left(\mathrm{mg} \mathrm{dm}^{-3}\right)$ & 9 & 11 \\
$\mathrm{P}\left(\mathrm{mg} \mathrm{dm}^{-3}\right)$ & 280 & 400 \\
$\mathrm{~K}\left(\mathrm{mmol}_{c} \mathrm{dm}^{-3}\right)$ & 2,8 & 3,4 \\
\hline
\end{tabular}

Fonte: Dados transcritos do laudo fornecido pelo Laboratório de Solos da UNESP/ FCAV. Extratores: pH: água; Al, Ca, Mg: KCl; H+Al: Ac. Cálcio; M.O.: Ac. Sulfúr.; $\mathrm{P}, \mathrm{K}, \mathrm{Cu}, \mathrm{Fe}, \mathrm{Mn}, \mathrm{Zn}$ : Mehlich; B: água quente.

\section{RESULTADOS E DISCUSSÃO}

As concentraçóes de $\mathrm{P}, \mathrm{K}, \mathrm{Mg}$ e Ca no solo (Tabela 1) podem ser consideradas acima do adequado, conforme recomendação de Natale et al. (1996). As concentrações de macronutrientes nas folhas de goiabeira obtidos neste experimento estão contidas na tabela 2. Comparando-se esses dados com as concentraçôes de nutrientes consideradas adequadas por Quaggio et al. (1996) e Natale (2003), os quais são $\mathrm{N}=13-16 ; \mathrm{P}=1,4-1,6 ; \mathrm{K}=13-16$; $\mathrm{Ca}=9-15 ; \mathrm{Mg}=2,4-4 \mathrm{~g} \mathrm{~kg}^{-1}$, observa-se que em todos os tipos de folhas e em ambas as épocas de avaliação, a concentraçáo de $\mathrm{N}$ esteve dentro da faixa considerada satisfatória. O P e o K estiveram deficientes nas folhas com sintoma visual leve e severo. As concentraçôes de $\mathrm{Ca}$ e de $\mathrm{Mg}$ estiveram abaixo do recomendado em todas as folhas analisadas, em ambas as épocas, exceto para $\mathrm{Ca}$ em folhas com sintoma severo, cujos teores foram mais elevados que as folhas nas demais situaçóes.

Quanto aos macronutrientes nas folhas avaliadas, as concentraçóes de N, P e K decresceram das folhas com ausência de sintoma para folhas com o sintoma leve e severo nas análises realizadas nas duas épocas. $\mathrm{O}$ Ca teve sua concentração aumentada com o agravamento dos sintomas, em ambas as épocas. Não houve alteração nas amostras com $\mathrm{Mg}$ coletadas em fevereiro. Em agosto, o Ca, $\mathrm{Mg}$ e $S$ tiveram suas concentraçóes maiores nas folhas com sintoma severo do que nas folhas com sintoma leve ou folhas com ausência de sintoma. O S teve uma concentração maior nas folhas com ausência de sintomas na análise realizada em fevereiro. $\mathrm{Na}$ análise realizada em agosto, as folhas com sintoma severo foram as que tiveram maiores concentraçôes desse nutriente.

Não houve diferença significativa entre as concentrações de $\mathrm{B}$ nas folhas analisadas em ambas as épocas de análise (Tabela 3). $\mathrm{O} \mathrm{Cu}$ e o Fe tiveram aumento de concentração de folhas com ausência de sintoma para as folhas com sintoma severo nas amostras obtidas em fevereiro. Exceção feita para a concentração de $\mathrm{Cu}$ em agosto, que não diferiu entre os sintomas. As concentrações de $\mathrm{Fe}$

Tabela 2. Concentração de macronutrientes em folhas de goiabeira cultivar Paluma com ausência de sintoma, com sintoma visual leve e severo de deficiência nutricional, causados pela infecção de Meloidogyne enterolobii, em amostras coletadas em fevereiro e agosto

\begin{tabular}{|c|c|c|c|c|c|c|}
\hline \multirow{3}{*}{ Folhas } & \multicolumn{6}{|c|}{ Nutrientes ( $\left.\mathbf{g ~ k g}^{-1}\right)$} \\
\hline & $\mathbf{N}$ & $\mathbf{P}$ & K & $\mathrm{Ca}$ & Mg & $\mathbf{S}$ \\
\hline & \multicolumn{6}{|c|}{ Fevereiro } \\
\hline Ausência de sintoma & 18,9 aA & $1,4 \mathrm{aA}$ & 17,3 aA & 8,7 bA & $1,7 \mathrm{aA}$ & $2,2 \mathrm{aA}$ \\
\hline Sintoma leve & $12,6 \mathrm{abA}$ & $0,6 \mathrm{bA}$ & $6,9 \mathrm{bB}$ & $8,7 \mathrm{bA}$ & $1,3 \mathrm{aA}$ & $1,4 \mathrm{bB}$ \\
\hline \multirow[t]{2}{*}{ Sintoma severo } & $13,1 \mathrm{bA}$ & $0,4 \mathrm{bA}$ & $5,1 \mathrm{cB}$ & $10,7 \mathrm{aA}$ & $1,2 \mathrm{aB}$ & $1,4 \mathrm{bB}$ \\
\hline & \multicolumn{6}{|c|}{ Agosto } \\
\hline Ausência de sintoma & 19,3 aA & $1,0 \mathrm{aA}$ & $15,3 \mathrm{aB}$ & $6,3 \mathrm{bB}$ & $1,4 \mathrm{bA}$ & $2,3 \mathrm{bA}$ \\
\hline Sintoma leve & $18,2 \mathrm{aA}$ & $0,9 \mathrm{aA}$ & $12,3 \mathrm{bA}$ & $6,6 \mathrm{bB}$ & $1,3 \mathrm{bA}$ & $2,4 \mathrm{bA}$ \\
\hline Sintoma severo & $14,4 \mathrm{bA}$ & $0,5 \mathrm{bA}$ & $7,1 \mathrm{cA}$ & $11,4 \mathrm{aA}$ & $2,3 \mathrm{aA}$ & $4,1 \mathrm{aA}$ \\
\hline CV (\%) & 19,57 & 16,29 & 6,64 & 12,84 & 13,79 & 12,42 \\
\hline
\end{tabular}

Médias seguidas da mesma letra minúscula na linha e maiúscula na coluna năo diferem entre si pelo teste de Tukey, a $5 \%$ de probabilidade. 
também foram semelhantes entre as épocas, exceto para folhas com sintoma severo, com teores significativamente maiores em agosto do que em fevereiro.

Em agosto, a concentraçáo de $\mathrm{Mn}$ aumentou das folhas assintomáticas para as folhas com sintomas severos. Com o $\mathrm{Zn}$, houve redução de concentração em folhas com ausência de sintoma para as folhas com sintomas severos, em ambas as épocas de avaliação. Em agosto, a concentração desse nutriente nas folhas com ausência de sintoma não diferiu da concentração nas folhas com sintoma leve. O Zn somente diferiu com relaçáo à época nas folhas com ausência de sintoma. Em fevereiro, os teores de nutrientes das folhas com ausência de sintoma foram maiores do que em agosto (Tabela 4).

Observa-se que houve desequilíbrio nutricional, refletido nos teores de macro e micronutrientes nas folhas, caracterizado por redução na concentração de $\mathrm{N}$, $\mathrm{P}$, K e $\mathrm{Zn}$ em folhas sintomáticas, em ambas as épocas. Houve aumento nas concentraçóes de $\mathrm{Ca}$ e Fe nas folhas sintomáticas e em relação aos demais nutrientes não ocorreram alteraçôes significativas em suas concentrações, ou os resultados foram dependentes da época de avaliação. Gomes et al. (2008) caracterizaram o desequilíbrio em goiabeiras infectadas nas condiçôes de São Joáo da Barra (RJ) com deficiência de $\mathrm{Ca}, \mathrm{Mg}, \mathrm{P}$ e K e excesso de $\mathrm{Cl}$ e B. É importante ressaltar que, no presente estudo, também ficou evidente que a infecção da

Tabela 3. Concentração de micronutrientes em folhas de goiabeira cultivar Paluma com ausência de sintoma, com sintoma visual leve e severo de deficiência nutricional, causados pela infecçáo de Meloidogyne enterolobii, em amostras coletadas em fevereiro e agosto

\begin{tabular}{|c|c|c|c|c|c|}
\hline \multirow{3}{*}{ Folhas } & \multicolumn{5}{|c|}{ Nutrientes $\left(\mathrm{mg} \mathrm{kg}^{-1}\right)$} \\
\hline & B & $\mathrm{Cu}$ & $\mathrm{Fe}$ & Mn & $\mathrm{Zn}$ \\
\hline & \multicolumn{5}{|c|}{ Fevereiro } \\
\hline $\begin{array}{l}\text { Ausência de } \\
\text { sintoma }\end{array}$ & $24,0 \mathrm{aA}$ & $10,0 \mathrm{bA}$ & $43,0 \mathrm{bA}$ & $171,0 \mathrm{aA}$ & $16,0 \mathrm{aA}$ \\
\hline Sintoma leve & 24,0 aA & $10,0 \mathrm{bA}$ & 126,0 aA & . $71,0 \mathrm{bB}$ & $10,0 \mathrm{bA}$ \\
\hline \multirow[t]{2}{*}{ Sintoma severo } & $23,0 \mathrm{aA}$ & $16,0 \mathrm{aA}$ & $153,0 \mathrm{aB}$ & $163,0 \mathrm{aB}$ & $7,0 \mathrm{cA}$ \\
\hline & \multicolumn{5}{|c|}{ Agosto } \\
\hline $\begin{array}{l}\text { Ausência de } \\
\text { sintoma }\end{array}$ & $24,0 \mathrm{aA}$ & $4,0 \mathrm{aB}$ & $63,0 \mathrm{cA}$ & $193,0 \mathrm{bA}$ & $13,0 \mathrm{aB}$ \\
\hline Sintoma leve & 25,0 aA & $4,0 \mathrm{aB}$ & $102,0 \mathrm{bA}$ & $200,0 \mathrm{bA}$ & $11,0 \mathrm{aA}$ \\
\hline Sintoma severo & 28,0 aA & $1,0 \mathrm{aB}$ & $275,0 \mathrm{aA}$ & $530,0 \mathrm{aA}$ & $7,0 \mathrm{bA}$ \\
\hline CV (\%) & 14,61 & 24,91 & 18,87 & 11,83 & 8,92 \\
\hline
\end{tabular}

Médias seguidas da mesma letra minúscula na coluna e maiúscula na linha não diferem entre si pelo teste de médias de Tukey, a 5\% de probabilidade. goiabeira por M. enterolobii acarretou alteraçôes fisiológicas que afetaram o metabolismo da planta, resultando em deficiências ou excessos nutricionais, os quais também caracterizaram os sintomas para esse patossistema. Conforme os dados das tabelas 1, 2 e 3, as deficiências de alguns nutrientes nas folhas náo são decorrentes de carências desses no solo das microparcelas, mas decorrem do comprometimento aos processos de absorção e transporte resultante da infecçáo pelo nematoide.

As discrepâncias nas concentraçôes de nutrientes em folhas observados no presente estudo e o relato de Gomes et al. (2008) podem ser creditados às diferenças no método, nas condiçôes edafoclimáticas das regiôes em questão, idade dos pomares e das variedades utilizadas, entre outras. Contudo, corroboram o fato de que há severa desordem nutricional com deficiência de alguns macronutrientes e concentração de outros micronutrientes.

Segundo Natale (2003), com relaçáo aos teores de nutrientes nas folhas de goiabeira para fins de diagnose, observa-se ampla variação nas informaçôes apresentadas na literatura, provavelmente, devido às diferentes recomendaçóes dadas quanto ao método de amostragem, havendo divergência em relação ao tipo de ramo e ao par de folhas a ser coletado para análise.

Na literatura, há relatos de desequilíbrio nutricional causados por nematoides em diferentes culturas. HurchaniK et al. (2004) observaram que, em cafeeiro (Coffea arabica L.) infectado por $M$. konaensis, nas condiçóes do Hawaii, a concentraçáo de $\mathrm{Ca}$ e $\mathrm{Mg}$ nas folhas decresceram e a de $\mathrm{Zn}$ aumentou em relação a plantas náo infectadas.

A adequada nutrição mineral representa para a goiabeira, assim como para todas as frutíferas, um dos aspectos mais importantes para alcançar o sucesso nessa atividade. De um lado, as exigências nutricionais da goiabeira são relativamente elevadas (Natale, 2003). De outro lado, o pleno desenvolvimento da planta é fortemente prejudicado pelo parasitismo do M. enterolobii, causando colapso na planta e culminando com o definhamento e, consequentemente, a morte.

Meloidogyne enterolobii provoca obstrução do xilema das raízes causando deficiência hídrica na folha, evidenciada pelo murchamento nas horas mais quentes do dia, e, consequentemente, reduçóes na condutância estomática e potencial hídrico. O fechamento parcial dos estômatos causa menor difusão de $\mathrm{CO}_{2}$ para os cloroplastos, diminuindo sua fixação. Inicialmente, a

Tabela 4. Fenologia da goiabeira 'Paluma' com e sem sintoma decorrido da infecção por Meloidogyne enterolobii. Períodos em cada evento dado em dias.

\begin{tabular}{lcccc}
$\begin{array}{l}\text { Evento/ } \\
\text { tratamento }\end{array}$ & $\begin{array}{c}\text { Iniciação floral } \\
\text { à antese }\end{array}$ & $\begin{array}{c}\text { Iniciação floral } \\
\text { à queda de pétalas }\end{array}$ & $\begin{array}{c}\text { Antese à queda } \\
\text { de pétalas }\end{array}$ & $\begin{array}{c}\text { Antese à maturação } \\
\text { dos frutos }\end{array}$ \\
\hline Com sintoma & $12,3 \mathrm{a}$ & $46,6 \mathrm{a}$ & $4,3 \mathrm{a}$ & $150,0 \mathrm{a}$ \\
Sem sintoma & $11,7 \mathrm{a}$ & $44,5 \mathrm{a}$ & $4,5 \mathrm{a}$ & $156,0 \mathrm{a}$ \\
CV $(\%)$ & 21,1 & 5,6 & 22,5 & 5,4 \\
\hline
\end{tabular}

Médias seguidas da mesma letra na coluna nấo diferem entre si pelo teste de médias de Tukey a $5 \%$ de probabilidade. 
fotossíntese fica limitada por processos difusivos, porém, com o agravamento da doença, todos os processos bioquímicos da planta passam a ser afetados (Perry e Moens, 2005).

Quanto à fenologia, não houve diferença estatística entre as fenofases das plantas inoculadas ou não-inoculadas com o nematoide (Tabela 4) sendo necessários de 150 a 156 dias, a partir da iniciação floral até a maturação das goiabas, no período de abril a setembro. Esses dados são semelhantes aos obtidos por Pereira e Nachtigal (2003). Esses autores mencionaram que as cultivares Rica e Paluma requereram cerca de 160 dias para que os botôes florais, recém-surgidos nos brotos, se transformassem em frutos maduros.

$\mathrm{Da}$ antese à maturação dos frutos foram necessários de 138 a 145 dias, no período de abril a setembro. Esses valores são semelhantes aos observados por Hojo et al. (2007) que relataram 148 dias entre a antese e a maturação dos frutos. Pereira (1995) também obteve resultados semelhantes em relação ao ciclo de maturação com duraçấo de 140 a 154 dias com as cultivares Pirassununga Vermelha, Pirassununga Branca, Brune Branca, Tetraplóide de Limeira e IAC-4 com um ciclo. O mesmo comportamento foi verificado por Pereira e SÁo José (1987), que constataram o desenvolvimento dos frutos com duração variável de 126 a 140 dias para as cultivares Rica e Paluma.

A época do ano tem destacada influência no desenvolvimento das fenofases da goiabeira. Segundo MercadoSiLva et al. (1998), no México, em um estudo com a cultivar Media China, na estação primavera-verão, observaram um ciclo de 130 dias, e no outono/inverno, um ciclo de 190 dias para alcançar a maturação.

Quanto à influência do parasitismo de $M$. enterolobii na fenologia da goiabeira são necessários estudos complementares para a avaliaçáo em outras épocas, como inverno/primavera, primavera/veráo e outono/inverno, pois a fenologia é um processo multivariado e suas variáveis são interligadas. Conforme observaram Hojo et al. (2007), o menor ciclo ocorrido nas épocas de poda pode ser decorrente da temperatura e da disponibilidade de água no solo, dada pela precipitação pluvial, posto que os períodos de menores ciclos, tanto a floração quanto a maturação dos frutos ocorreram em períodos de temperaturas médias mais elevadas. Portanto, como o parasitismo do nematoide na planta influencia a disponibilidade de água e nutrientes, é possível haver influência na fenologia da goiabeira em outras épocas do ano que não foram avaliadas neste trabalho.

\section{CONCLUSÃO}

A infecção de $M$. enterolobii em goiabeira influencia a concentração de nutrientes nas folhas de forma que se observam níveis de deficiência de N, P, K e Zn, com aumento dos teores de $\mathrm{Ca}$ e $\mathrm{Fe}$ devido ao agravamento dos sintomas. A infecção por $M$. enterolobii não altera a fenologia da goiabeira no período de verão/outono.

\section{AGRADECIMENTO}

À Fundação de Amparo a Pesquisa do Estado de São Paulo - FAPESP , pelo auxílio à pesquisa concedido sob número 06/57048-1.

\section{REFERÊNCIAS}

BARKER, K.R.; PEDERSON, G.A.; WINDHAM, G.L. Plant and nematode interaction. Madison: ASA, CSSA, SSSA, 1998. 771p.

CARNEIRO, R.M.D.G.; MOREIRA, W.A.; ALMEIDA, M.R.A.; GOMES, A.L.M.M. Primeiro relato de fitonematóide Meloidogyne mayaguensis parasitando goiabeira (Psidium guajava L.) cv. Paluma. Nematologia Brasileira, v.25, p.55-57, 2001.

CORRÊA, M.C.M.; PRADO, R.M.; NATALE, W.; SILVA, M.A.C.; PEREIRA, L. Índice de pegamento de frutos em goiabeiras. Revista Brasileira de Fruticultura, v.24, p.783-786, 2002.

GOMES, V.M.; SOUZA, R.M.; SILVA, M.M.; DOLINSKI, C. Caracterizaçáo do estado nutricional de goiabeiras em declínio parasitadas por Meloidogyne mayaguensis. Nematologia Brasileira, v.32, p.154-160, 2008.

HOJO, R.H.; CHALFUN, N.N.J.; HOJO, E.T.D.; SOUZA, H.A.; PAGLIS, C.M.; SÃO JOSÉ, A.R. Caracterização fenológica da goiabeira 'Pedro Sato' sob diferentes épocas de poda. Revista Brasileira de Fruticultura, v.29, p.20-24, 2007.

HURCHANIK, D.; SCHMITT, D.P.; HUE, N.V.; SIPES, B.S. Plant Nutrient Partitioning in Coffee Infected with Meloidogyne konaensis. Journal of Nematology, v.36, p.76-84, 2004.

HUSSEY, R.S. Host-parasite relationships and associated physiological changes. In: SASSER, J.N.; CARTER, C.C. (Eds.). An advanced treatise on Meloidogyne: biology and control. Raleigh: North Carolina State University, 1985, p.143-153.

HUSSEY, R.S.; BARKER, K.R. A comparison of methods of collecting inocula of Meloidogyne spp., including a new technique. Plant Disease Reporter, v.57, p.1025-1028, 1973.

MERCADO-SILVA, E.; BENITO, P.B.; VELASCO, M.A.G. Fruit development, harvest index and ripening changes of guavas produced in central Mexico. Postharvest Biology and Technology, v.13, p.143-150, 1998.

NATALE, W.; COUTINHO, E.L.M.; BOARETTO, A.E.; PEREIRA, F.M. Goiabeira: calagem e adubação. Jaboticabal: FUNEP, 1996. 22p.

NATALE, W. Calagem, adubação e nutrição da cultura da goiabeira. In: ROZANE, D.E.; COUTO, F.A.d'A. (Ed.). Cultura da goiabeira: tecnologia e mercado. Viçosa: UFV, 2003. p.303-332. 
PEREIRA, F.M. Cultura da goiabeira. Jaboticabal: FUNEP, 1995. 47p.

PEREIRA, F.M.; NACHTIGAL, J.C. Melhoramento da goiabeira. In: ROZANE, D.E.; COUTO, F.A.d'A. (Ed.). Cultura da goiabeira: tecnologia e mercado. Viçosa: UFV, 2003. p.53-78.

PERRY, R.N.; MOENS, M. Plant nematology. Pondicherry: Biddles, 2005. 447p.

QUAGGIO, J.A.; van RAIJ, B.; PIZA Jr., C.T. Frutíferas. In: van RAIJ, B.; CANTARELLA, H; QUAGGIO, J.A.; FURLANI,
A.M.C. (Ed.). Recomendaçôes de adubação e calagem para o Estado de São Paulo. 2.ed. Campinas: IAC, 1996. p.21-25. (Boletim Técnico, 100)

TAIZ, L.; ZEIGER, E. Fisiologia Vegetal. 3.ed. Porto Alegre: Artmed, 2004. 720p.

TEDESCO, M.J.; GIANELLO, C.; BISSANI, C.A.; BOHNEN, H.; VOLKWEISS, S.J. Análise de solo, plantas e outros materiais. Porto Alegre: Universidade Federal do Rio Grande do Sul, 1995. 174p. 